\title{
Native and Adapted Plant Introduction for Low-water Landscaping
}

\author{
Larry A. Rupp ${ }^{1,5}$, Richard M. Anderson ${ }^{2}$, James Klett ${ }^{3}$, \\ Stephen L. Love ${ }^{4}$, Jerry Goodspeed ${ }^{2}$, and JayDee Gunnell ${ }^{2}$
}

\begin{abstract}
ADDITIONAL INDEX WORDs. drought, germplasm release, plant patent, plant trademark, evaluation, royalty

SUMMARY. In response to a perceived need for the development and introduction of superior plant accessions for use in sustainable, low-water landscaping, land-grant universities in Colorado, Idaho, and Utah, have supported plant development programs. Each of these programs has unique characteristics and protocols for releasing plant materials and obtaining royalties to further support research and development. Colorado State University (CSU) is part of the Plant Select program, which evaluates and promotes native and non-native plants for use in low-water landscapes. Selected plants are released to commercial members who pay a membership fee and royalties for access to the selected plants. The University of Idaho focuses on selecting and evaluating native herbaceous perennials, which are then released through a contract and royalty program with a local nursery. Utah State University uses the Sego Supreme program to select, propagate, and evaluate native plants. Selected plants are released to interested growers who pay a royalty for production rights.
\end{abstract}

$\mathrm{T}$ he response to drought within regions of the United States has revealed a tendency to reduce the quality of landscaping in the name of water conservation (Hartin et al., 2017; Kuznia, 2015; Reid and Oki, 2013). Given that in many urban areas, landscaping is the de facto environment; it would seem shortsighted to replace live plant materials with artificial turf or other hardscapes. This conversion also risks reducing amenities that society may take for granted. These amenities are clearly illustrated by the reaction of a young

This article results from the workshop "Maintaining Healthy Landscapes Under Drought and/or Permanent Water Restrictions" held on 20 Sept. 2017, at the ASHS Annual Conference, Waikoloa, HI, and sponsored by the Ornamentals/Landscape and Turf $(\mathrm{O} / \mathrm{LT})$ Professional Interest Group.

This research was supported by the Utah Agricultural Experiment Station, Utah State University, and approved as journal paper number 9091 .

Mention of a trademark, proprietary product, or vendor does not constitute a guarantee or warranty of the product by the authors or sponsoring entities and does not imply its approval to the exclusion of other products or vendors that also may be suitable.

${ }^{1}$ Plants, Soils, and Climate Department, Utah State University, Logan, UT 84322

${ }^{2}$ Utah State University Botanical Center, Kaysville, UT 84037

${ }^{3}$ Horticulture and Landscape Architecture Department, Colorado State University, Fort Collins, CO 80521

${ }^{4}$ Aberdeen Research and Extension Center, University of Idaho, Aberdeen, ID 83210

${ }^{5}$ Corresponding author. E-mail: larry.rupp@usu.edu.

https://doi.org/10.21273/HORTTECH04044-18
Wallace Stegner when he first saw a lawn: "I was nearly 12 before I saw either a bathtub or a water closet; and when I walked past my first lawn, ... I stooped down and touched its cool nap in awe and unbelief. I think I held my breath - I had not known that people anywhere lived with such grace" (Stegner, 1948).

Stegner saw his first lawn in Great Falls, MT, after being raised on a homestead with a yard "bare as an alkali flat." His account illustrates a common experience in the dry interior western and southwestern states where amenity landscaping can offer a welcome respite from often harsh environments. In the last century, the states of Colorado, Idaho, and Utah averaged 18,24, and 14 inches of annual precipitation, respectively (National Oceanic and Atmospheric Administration, 2015). Preserving the quality of life gained from amenity landscapes in these and surrounding states often requires supplemental irrigation. Unfortunately, a desire to preserve landscapes does not address the very real need to conserve water use in these areas.
Water conservation is a complex issue and a successful campaign requires multiple approaches. One approach is the use of drought-tolerant plants. The full spectrum of drought-tolerant landscape plants includes both exotic plants (plants not present before western colonization and adapted to the landscaped environment) and/or native plants [for the purposes of this article, species originating anywhere within the Intermountain West region of the United States that are sufficiently adapted to the intended planting environment as to be sustainable with limited supplemental irrigation (Fig. 1)]. Native plants hold the promise of tolerance to local environments, reduced potential for invasiveness, and the ability to support pollinators and other native wildlife (Dole, 2016). It might also be surmised that such plants can be effectively propagated and produced in their native environment. It is further worth noting that local or regional adaptation is necessary in the Intermountain West where tremendous geographic variation can render a plant native to one region of a state (such as high elevation mountain meadows) ineffective in other regions (such as low elevation urban landscapes).

Native plants have been produced and sold for decades for use in reclamation and other applications (Monsen, 2004). Selection of some native plant species for the landscape industry has also occurred for hundreds of years. A good example is redosier dogwood (Cornus sericea), which has been cultivated since 1656 (Dirr, 1975). Most native plants currently grown for the landscape industry are relatively well adapted to nursery production-and to mesic habitats-making them excellent candidates for planting in traditional irrigated landscapes. With the impetus of water conservation and probable future restrictions, the landscape industry is looking at plants that may be more drought and stress tolerant. But, such plants may also require specific soil conditions, unspecified symbiotic microorganisms,

\begin{tabular}{llll}
\hline $\begin{array}{l}\text { Units } \\
\text { To convert U.S. to SI, } \\
\text { multiply by }\end{array}$ & U.S. unit & SI unit & $\begin{array}{l}\text { To convert SI to U.S., } \\
\text { multiply by }\end{array}$ \\
\hline 0.4047 & acre(s) & ha & 2.4711 \\
2.54 & inch(es) & $\mathrm{cm}$ & 0.3937
\end{tabular}




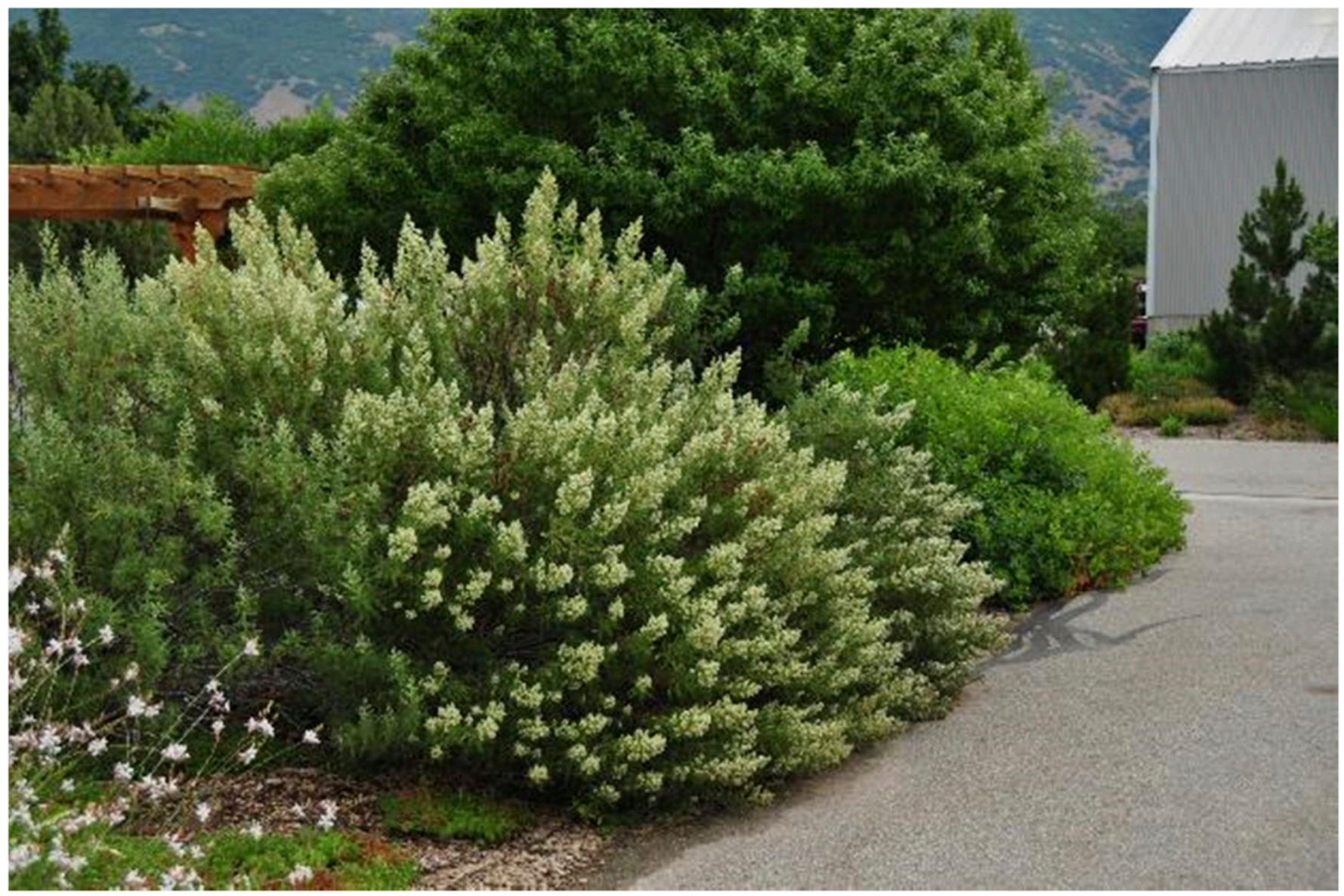

Fig. 1. Use of the Utah native plant, fernbush (Chamaebatiaria millifolium), in a demonstration garden highlighting native and adapted plants.

and protection from irrigationinduced diseases (Dumroese et al., 2008; Swiecki and Bernhardt, 2017). In Utah, native plants can be highly uniform [such as the quaking aspen (Populus tremuloides) clone Pando that occupies 106 acres and $\approx 47,000$ stems], or they can be genetically very diverse, as is expressed in sagebrush (Artemisia) species and varieties (DeWoody et al., 2008). Diversity is key to successful wildland reclamation, but is often contrary to the goals of landscape horticulture where uniformity of nursery production and landscape performance is critical to customer satisfaction. To be successful, plant development programs must meet multiple coincidental objectives, such as matching desirable horticultural characteristics with product uniformity. Several different plant development and release program models have arisen in the interior western states to support the selection, production, evaluation, and marketing of native plants.

\section{Materials and methods}

Utah MOdel. The Sego Supreme plant breeding and introduction program was initiated by Utah State University's Botanical Center in 2012 to support efforts by Utah State University researchers to develop native plants. Specifically, its goal is to develop and promote superior native plant varieties that demonstrate adaptability to urbanized landscapes of the western United States. Although the program is regional in focus, the program's plants are selected with the intent that they can also be grown successfully in zone-appropriate regions throughout North America. Sego Supreme currently works with industry professionals in Utah, Idaho, Colorado, and California who trial, produce, and market its plant selections to regional and national entities.

The herbaceous plant component of the program seeks to collect native flowering perennials from the wild and cultivate them in a common garden setting where plants with superior ornamental traits can be identified and selected. Seeds or vegetative material from a selection are used to complete additional cycles of reproduction and establishment, and supplementary evaluation for hardiness, wide adaptability to climate and soils, water efficiency, habit uniformity, attractiveness and longevity of blooms, noninvasiveness, pest and disease resistance, and ease of propagation. The selection process averages 5 years; however, 8 years or more is not uncommon. To date, four perennial selections have been commercially released. These include 'Sol Dancer' arizona four-nerve daisy (Tetraneuris acaulis var. arizonica), 'Wasatch Fire' hummingbird trumpet (Epilobium canum ssp. garrettii), 'Uvatün' broadleaf beardtongue (Penstemon platyphyllus), and 'Purple Chip' purple sage (Salvia dorrii var. clokeyi).

Sego Supreme also has a woody plant component based on in situ selection and clonal propagation of 
native species. Because of their slow growth habits and recalcitrance to propagation, woody species generally take a longer period for development and evaluation. Once an accession is effectively propagated, evaluation in the landscape then begins. In addition to in-house evaluation, where feasible, accessions have been submitted to the Colorado Plant Select program for a 3-year evaluation period in their trial garden system. Plants deemed to be superior accessions are then slated for release to the landscaping industry.

Initial selection of woody plants is focused largely on aesthetic values such as fall color, leaf characteristics, and form. Research is also conducted on vegetative propagation requirements. Many Utah native plants, such as bigtooth maple (Acer saccharum var. grandidentatum), are not widely used in the industry. This may be due in part to challenges in propagation and production. It is difficult to vegetatively propagate wild woody plants that may be under various stresses as compared with stock plants in a nursery. However, once such plants are established in a nursery environment, it is possible to delineate propagation requirements. Through effective research with nursery grown stock, propagation success has improved significantly with some species (Richards and Rupp, 2012).

Each plant selection, before any commercial release of plant material, must go through several administrative steps. The first step requires the selection to be reviewed by a committee of Utah Agricultural Experiment Station researchers. Second, when plant selections are approved for commercial release, the breeder/developer works with the university's Technology Transfer Services (TTS) to develop logos and tags, seek trademarks, and ensure intellectual and legal protection for the selection. Third, the breeder/developer works with TTS to recruit and license growers to produce and distribute the selection. A royalty collected for plants sold by licensed growers is used to further support similar research in the future.

IDAHO MODEL. Through funding derived from the U.S. Department of Agriculture (USDA) Specialty Crops Block Grant program and funds from the Idaho State Department of
Agriculture, the University of Idaho Aberdeen Research Station has developed an extensive program for the development of native perennial herbaceous and woody plants. The annual cost of the acquisition and evaluation program, including both University of Idaho grant agency contributions, is $\approx \$ 35,000$.

To maximize product development potential, Idaho researchers use a definition of "native" that includes species originating anywhere within the Intermountain West region of the United States. The Idaho program depends primarily on seed propagation and is based on a high-volume approach to selection of superior waterconserving plant products. Source materials are collected en masse by program personnel via seed or cutting, or alternately are purchased from professional collectors and native plant societies. The native plant development program was started in 2005 . As of 2017, more than 3600 accessionsrepresenting $\approx 1200$ species-of native plants have been acquired and evaluated for landscape potential.

Once accessions are acquired, researchers apply a brief domestication protocol to improve uniformity and horticultural value by applying one to four rounds of mass selection to each accession. This process requires from 4 to 12 years to complete for each species evaluated. Inferior accessions are eliminated during the selection process. Superior selections are established in a permanent seed block at the research center in Aberdeen, ID.

Once accessions are deemed acceptable, seed material is provided to the nursery industry for further seed increase and active marketing. In 2011, a partnership agreement was signed with Native Roots, LLC (Twin Falls, ID), providing exclusive access to intellectual property through a licensed collaboration. These plants are marketed under Native Roots as a branded line of native plants for residential and commercial applications. Compensation for the intellectual property is in the form of a $5 \%$ royalty fee on final sales paid by Native Roots, LLC to the University of Idaho-Office of Technology Transfer. Under the license, Native Roots, LLC has copartnered with numerous wholesale and retail nurseries to distribute these native plant products on a broader scale.

To date, Native Roots, LLC has received more than 110 market-ready native plant species from the University of Idaho. From these potential native plant products, the company has established an advertised line consisting of 47 herbaceous perennials, grasses, and shrubs. The highest sales volume to date has been derived from the following species: threadleaf giant hyssop (Agastache rupestris), desert columbine (Aquilegia desertorum), utah columbine (Aquilegia scopulorum), prairie sagewort (Artemisia frigida), sulfur-flower buckwheat (Eriogonum umbellatum var. dichrocephalum), idaho fescue (Festuca idahoensis), stemless four-nerve daisy ( $T$. acaulis), colorado four o'clock (Mirabilis multiflora), cardinal beardtongue (Penstemon cardinalis), pineneedle beardtongue (Penstemon pinifolius), rocky mountain beardtongue (Penstemon strictus), lewis' mockorange (Philadelphus lewisii), sandberg bluegrass (Poa secunda), scarlet cinquefoil (Potentilla thurberi), blue sage (Salvia pachyphylla), big sacaton (Sporobolus wrightii), and rocky mountain zinnia (Zinnia grandiflora). In 2018, five additional products will be offered by Native Roots, LLC, including hummingbird's mint (Agastache cana), bluebell bellflower (Campanula rotundifolia), owl's-claws (Helenium hoopesii), sandia mountain alumroot (Heuchera pulchella), and venus beardtongue (Penstemon venustus). The partnering company, with cooperation from the University of Idaho, has plans to release five new native plant products each year.

One objective of the Idaho native plant domestication project is to become financially self-supporting. Royalties from our industry partner, Native Roots, LLC, makes this feasible as demand for water-conserving native plants grows.

\section{Colorado model}

Plant Select is a very successful plant introduction and promotion program for the Rocky Mountain and plains states. It was started more than 30 years ago as a joint effort of the Denver Botanic Garden (DBG) and CSU, with assistance from members of the green industry. Initially, the program was envisioned primarily as a means of introducing outstanding 
woody plants from the region. The program struggled for many years, but in 1996, a pivotal change occurred which sparked the program into action. The change was to focus primarily on promoting novel herbaceous perennial plants (many native) in addition to woody plants. This new focus galvanized cooperation with the Colorado Nursery and Greenhouse Association (CNGA).

Originally, Plant Select was equally administered by the three cooperating entities (DBG, CSU, and CNGA). In 2006, it became a Colorado cooperative. Under this new organizational structure, a six-member board of directors, comprising two representatives from each of the three participating agencies, was appointed. In 2008, the program's first full-time paid position was created (executive director) and this person is currently responsible for administering the program.

The criteria for selecting plants for the program include the following: performance in a broad range of garden situations in the Rocky Mountain region, adaptation to the region's challenging climate, uniqueness of flower color or plant habit, disease and insect resistance, exceptional performance under low water conditions, a long season of beauty with an emphasis on fall color, interesting fruit, winter appeal, noninvasiveness in the landscape, and capacity to be mass produced. Germplasm for the program has been selected from outstanding living collections held at DBG, existing highly desirable landscape plants that need commercial promotions, the commercial sector, and a regional USDA plant introduction station. Original acquisition methods include selections from regional and international field collecting ventures, selection of natural sports within populations of commercially available varieties, and botanical garden's seed lists. Some promotions have been the result of selection from plant breeding programs.

Sample germplasm is distributed for trial at various locations throughout Colorado where prospective selections are evaluated for minimum of 3-5 years before being released for sale. Variety names are established for selections that warrant such distinction, trademark names linking the promotion with the Plant Select program are filed with U.S. Patent and Trademark Office, whereas selections with a unique genotypic character receive a name for which a patent is sought.

One or more commercial participants take responsibility for increasing the germplasm stock to predetermined numbers required for distribution and sales. Commercial organizations pay membership dues to Plant Select to secure rights to the popular promotional selections. In addition, royalties are paid to Plant Select for the sale of each plant. Royalty values vary depending on whether the plant is an introduction, a recommendation, an annual, a perennial, woody species, trademarked, or patented.

Each year the new introductions are widely promoted in four-color brochures, newspaper articles, websites (Plant Select, 2018), social media, and banners and posters at both garden centers and many state and national horticultural conferences. Plants are also given to public demonstration gardens throughout the region. Managers of these demonstration gardens also conduct ongoing evaluations of each variety's performance, submitting their reports to the program. Since the flagship promotion in 1997, more than 140 selections have been featured and more than 30 million plants have been sold.

\section{Discussion}

Looking back over the Utah, Idaho, and Colorado native and adapted plant development programs, questions arise as to optimal procedures for successful introduction of potentially valuable products. There are clearly differences between programs with Colorado's being the oldest and most successful, Idaho's being very streamlined in its application, and Utah's still in its infancy. Development protocols depend in part on researcher priorities. At one extreme, a program can espouse elements of in-depth physiological research, thus limiting the number of native plant species evaluated, whereas at the same time potentially providing greater understanding of a selection's production requirements and meeting the scholarship requirements of a researcher's institution. If the program is research focused and resources are limited, it is easy to be so focused on the research goals that opportunities to release plant material might be missed. At the other extreme, a program can be created which focuses on product development and release, thereby increase the flow of material through the program but with limited research on any given species. New program development would benefit from a careful assessment of the goals of researchers, collaborators, and administrative or granting agencies.

Another question when working toward new plant releases is whether the program should be stepwise (identify, collect, elucidate propagation, evaluate in landscape, and then release) or concurrent (identify, collect, and elucidate propagation while simultaneously evaluating in the landscape, and then release). With slow-growing woody plants, the latter approach can save literally years in the development of a plant. But, it also requires more time and effort to keep multiple aspects of a research program functioning simultaneously.

Other problems include a practical definition of natives to help define research objectives, soil-borne diseases common to gardens but apparently absent in the native environment, and phenotypic variability that reduces product desirability. In much of the Intermountain area and west coast there is wide variation in topography, which affects frost-free season length, soil types, and other environmental factors. Native plants may be adaptable to a wide range of environmental conditions or highly specific in their requirements. If selected plants are not well adapted to the landscape environment, the results may range from changing phenotypes to mortality. In short, just because a plant is native does not mean it is adapted to landscape use in the intended market area.

Thomas Jefferson said "The greatest service which can be rendered any country is to add a useful plant to its culture..." (Jefferson, 1800). This observation may prove true as continuing efforts are made to balance the aesthetic benefits of landscaping with the reality of drought and subsequent need for water conservation. It is apparent that different native and adapted plant development strategies can be successfully used to introduce unique accessions to the marketplace. Future development models will likely be a function of consumer demand for native plants, local opportunities for industry collaboration and support, and external factors driving the market 
such as climate change and drought. Nursery growers, landscape architects, researchers, and others should monitor the use and demand for native plants and their role in overall landscape water conservation to gauge the next steps in developing this underused resource.

\section{Literature cited}

DeWoody, J., C.A. Rowe, V.D. Hipkins, and K.E. Mock. 2008. "Pando" lives: Molecular genetic evidence of a giant aspen clone in central Utah. West. N. Amer. Nat. 68:493-497.

Dirr, M.A. 1975. Manual of woody landscape plants: Their identification, ornamental characteristics, culture, propagation and uses. Stipes Publ., Champaign, IL.

Dole, J.M. 2016. Reflections: Native plants. Amer. Soc. Hort. Sci. Nwsl. 32(11):3-6. 16 May 2018. <http://c.ymcdn.com/ sites/www.ashs.org/resource/resmgr/ Reflections/Native_Plants.pdf>.

Dumroese, R.K., T. Luna, and T.D. Landis (eds.). 2008. Nursery manual for native plants: A guide for tribal nurseries. U.S. Dept. Agr., For. Serv. Agr. Hdbk. 730.

Hartin, J., L. Oki, D. Fujino, K. Reid, C. Ingels, and D. Haver. 2017. Evapotrans- piration adjustment factor study: Final project report. California Dept. Water Resources, Office Water Use Efficiency, Sacramento.

Jefferson, T. 1800. Jefferson quotes and family letters. 16 May 2018. <http://tjrs. monticello.org/letter/188\#X3184736>.

Kuznia, R. 2015. California turns to fake grass in response to drought. Washington Post 23 May 2015. 16 May 2018. <https:// www.washingtonpost.com/national/indrought-plagued-california-the-grassis-getting-greener $/ 2015 / 05 / 23 /$ 7lcl4b2e-ffl3-11e4-805c-c3f407e5a9e9 story.html?noredirect $=$ on\&utm_term $=$. $74 \mathrm{f} 093558 \mathrm{~d} 8 \mathrm{~d}>$.

Monsen, S.B. 2004. History of range and wildlife habitat restoration in the Intermountain West, p. 1-6. In: S.B. Monsen, R. Stevens, and N.L. Shaw (eds.). Restoring western ranges and wildlands. U.S. Dept. Agr., For. Serv., Rock Mountain Res. Sta., Gen. Tech. Rpt. RMRS-GTSR136-vol 1.

National Oceanic and Atmospheric Administration. 2015. State of the climate: National climate report for annual 2014.
17 May 2018. <https://www.ncdc.noaa. gov/sotc/national/201413>.

Plant Select. 2018. Plant Select plant smarter. 16 May 2018. <http:// plantselect.org $>$.

Reid, K. and L. Oki. 2013. Irrigation and climate zone trials of perennial plants for sustainable landscapes. Acta Hort. 980:95-102.

Richards, M.R. and L.A. Rupp. 2012. Etiolation improves rooting of bigtooth maple cuttings. Hort Technology 22:305310.

Stegner, W.E. 1948. Marking the sparrow's fall: The making of the American West. Henry Holt, New York, NY.

Swiecki, T.J. and E.A. Bernhardt. 2017. Phytophthora in nursery stock and restoration plantings. 16 May 2018 . <http:// phytosphere.com/soilphytophthora/ Issues_implications_Phytophthora_ container_stock.htm>. 